\title{
Caracterización del pago de impuesto a la renta de primera categoría por el concepto de alquiler de inmuebles para vivienda de la ciudad de Chachapoyas, 2015 \\ Characterization of the payment of first class income tax for the concept of renting of housing for the city of Chachapoyas, 2015.
}

\author{
Carlos A. Hinojosa Salazar ${ }^{1}$
}

\section{RESUMEN}

La presente investigación, tuvo por objetivo realizar la caracterización del pago de impuesto a la renta de primera categoría por el concepto de alquiler de inmuebles para vivienda en la ciudad de Chachapoyas, 2015. La investigación fue aplicada, donde se utilizó un enfoque cuantitativo, de nivel descriptivo, con un diseño no experimental. El estudio comprendió una población de 6077 , teniendo como muestra a 173 participantes a quienes se les realizó la encuesta correspondiente. Como resultado se detectó que un $70 \%$ de los propietarios no paga el impuesto por el alquiler de sus inmuebles; si existiera una verdadera conciencia tributaria redundaría en un mayor crecimiento del PBI del departamento. Las conclusiones reflejan que el arriendo se caracteriza por ser un negocio exitoso, pero, que en ciertos casos existe evasión tributaria.

Palabras clave: Caracterización, Impuesto a la renta, Primera categoría, Cultura Tributaria.

\begin{abstract}
The objective of the present investigation was to characterize the payment of first class income tax for the concept of renting housing for housing in the city of Chachapoyas, 2015. The research was applied, where a quantitative approach was used. Descriptive level, with a non-experimental design. The study comprised a population of 6077 , with a sample of 173 participants who were surveyed. As a result it was detected that $70 \%$ of the owners do not pay the tax for the rent of their properties; If there was a true tax consciousness would result in a greater growth of the department's GDP. The conclusions reflect that the lease is characterized by being a successful business, but, in certain cases there is tax evasion.
\end{abstract}

Keywords: Characterization, Income tax, First category, Tax culture

'Docente Asociado de la Facultad de Ciencias Económicas y Administrativas de la Universidad Nacional Toribio Rodríguez de Mendoza de Amazonas. Contador Público. Doctor en Administración, Universidad Nacional de Trujillo. Magister en Ciencias Económicas, mención Finanzas, Universidad Nacional de Trujillo. Correo electrónico: carlos.hinojosa@untrm.edu.pe 


\section{INTRODUCCIÓN}

E1 Presupuesto de la República se financia en mayor porcentaje con los ingresos provenientes de la recaudación tributaria y esta no ha podido crecer de acuerdo a lo deseado, debido a que los contribuyentes son renuentes a cumplir con sus obligaciones tributarias, incurriendo en evasión de los tributos. Esto se convierte en un gran problema que ocasiona la disminución de la recaudación de los ingresos fiscales, los mismos que sirven para financiar las actividades que realiza el estado. Como se conoce, la recaudación fiscal permite al estado atender las necesidades de la población en lo social, educativo, salud, seguridad, entre otros; pero cuando los contribuyentes evaden sus obligaciones tributarias disminuye la recaudación de ingresos, afectando al presupuesto que se destina a brindar dichos servicios.

Para que el Perú pase al nivel de una economía desarrollada requiere una mejora de la calidad de sus políticas públicas y mejores instituciones. Chile, a pesar que su economía tiene un importante nivel primario, se viene acercando al nivel de las economías desarrolladas, justamente porque viene mejorando sus políticas públicas y sus instituciones. Por esta razón el 2012 Chile registró los más altos niveles de PBI per cápita de la región sudamericana.

El Perú es la quinta economía más informal del mundo, pues alrededor del $60.9 \%$ de nuestra economía existe al margen de la ley.

En la ciudad de Chachapoyas, los últimos 20 años ha crecido vertiginosamente con la construcción de nuevas viviendas. Según datos de la Empresa de Agua Potable y Alcantarillado de Amazonas (Emusap Amazonas S.R.L.), actualmente se cuenta con 6077 usuarios activos que cuentan con el servicio de agua potable y alcantarillado. Dichos propietarios para poder sobrevivir por la carestía de trabajo arriendas sus casas, tanto a instituciones públicas, privadas y otros y de esa manera obtener algunos ingresos adicionales, pero muchos de ellos sin pagar el impuesto correspondiente notándose un desbalance patrimonial.

(Aznarán y Sánchez, 2011), en su investigación sostienen que la recaudación de las rentas de primera categoría por alquiler de bienes inmuebles, no tiene el mismo dinamismo que las otras rentas. Esto se debe al escaso control de la Superintendencia Nacional de Administración Tributaria (Sunat) en la administración del impuesto a la renta de primera categoría.

Por otra parte, (Rivas y Paillacar, 2007), en su artículo científico afirman que la distancia entre la recaudación tributaria esperada y la recaudación obtenida, corresponde a la evasión tributaria. El origen de este problema es que no se han analizado con profundidad y rigurosidad algunas situaciones relacionadas con materias impositivas que generan "zonas grises" respecto de las conductas frente a la estructura administrativa tributaria. En este aspecto, el caso más representativo puede ser el límite entre la elusión y la evasión. Por una parte se requiere estudiar la evasión fiscal dado que implica la verificación del hecho generador tributario y el posterior incumplimiento de la obligación emergente y por otra parte, la elusión fiscal consiste en la no verificación del hecho generador tributario y por ello en la inexistencia de gravamen. La investigación tuvo como objetivo realizar la caracterización del pago de impuesto a la renta de primera categoría por el concepto de alquiler de inmuebles para vivienda de la ciudad de Chachapoyas.

\section{MATERIAL Y MÉTODOS}

La investigación realizada fue del tipo aplicada, descriptiva debido a que hace uso los conocimientos básicos para generar conocimiento específico relacionado con la investigación; por sus características y presentación de los resultados es de tipo cuantitativa, bajo un enfoque holístico, para identificar las características del pago de impuesto a la renta de primera categoría por el concepto de alquiler de inmuebles para vivienda en la ciudad de Chachapoyas, 2015.

El estudio se aplicó a una muestra de 173 pobladores obtenidos a través del muestreo aleatorio simple de un total de 6077 habitantes con inmuebles para vivienda registrados en la base de datos de la Empresa de Agua Potable y Alcantarillado de Amazonas (Emusap Amazonas S.R.L.).

Como instrumento para el acopio de información se utilizó una encuesta elaborada teniendo como criterio cumplir con el objetivo general; formulándose siete preguntas que han permitido caracterizar el estudio.

\section{RESULTADOS}

Identificación de los propietarios de los inmuebles del distrito de Chachapoyas. 


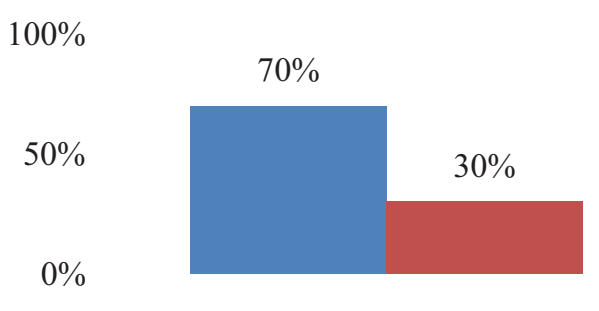

$\square \mathrm{Si}=\mathrm{No}$

Figure 1. Alquiler de su propiedad.

En la figura 1, el $70 \%$ de los encuestados afirmaron si alquilan su vivienda, el resto de la población de estudio respondió negativamente.

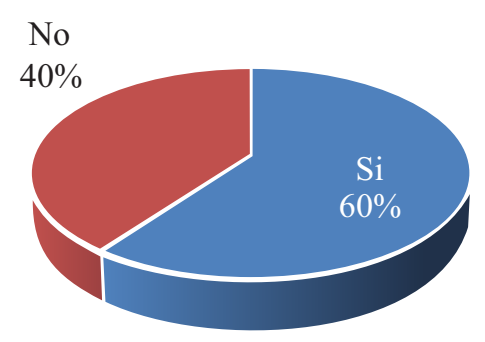

Figure 2. Gastos para brindar el servicio de alquiler.

En la figura $\mathrm{N}^{\circ} 2$, el $60 \%$ afirmó realizar algunos gastos para brindar el servicio de alquiler, el porcentaje restante respondió negativamente.

\section{$\square \mathrm{Si}$ No}

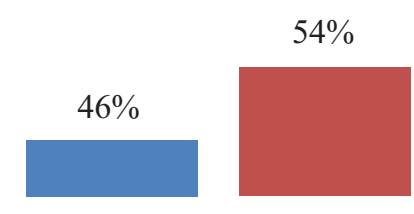

Figure 3. Sustento documentado (boletas y/o facturas) respecto al gasto que realiza.

En la figura $\mathrm{N}^{\circ} 3$, el $54 \%$ de los entrevistado dijo no tener sustento documentado respecto al gasto que realiza, el $46 \%$ respondió de forma afirmativa.

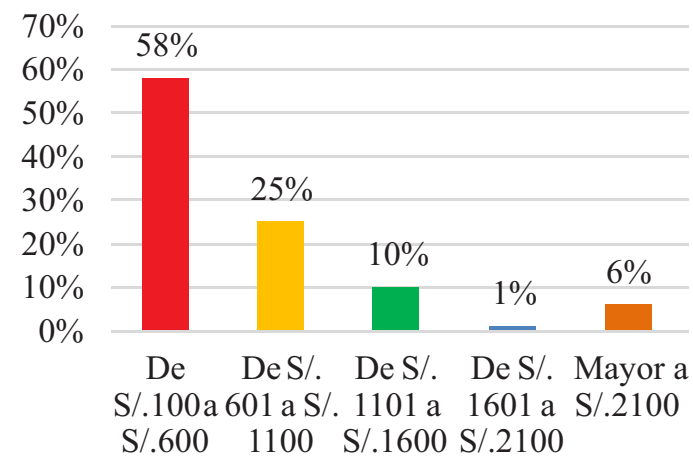

Figure 4. Importe mensual percibido por el alquiler de su inmueble.

En la figura $\mathrm{N}^{\circ} 4$, se muestra el importe mensual percibido por el alquiler del inmueble, en el cual el $58 \%$ respondió percibir de $\mathrm{S} / .100$ a $\mathrm{S} / .600$, el $25 \%$ entre S/.601 a S/.1 100.

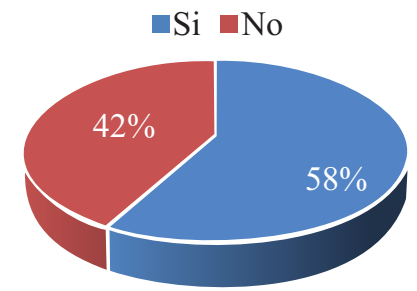

Figure 5. Emisión de comprobante que sustente el pago del alquiler.

En la figura $\mathrm{N}^{\circ} 5$, se muestra que el $58 \%$ de los entrevistados no emite comprobante que sustente el pago del alquiler, el porcentaje restante respondió que si lo hace.

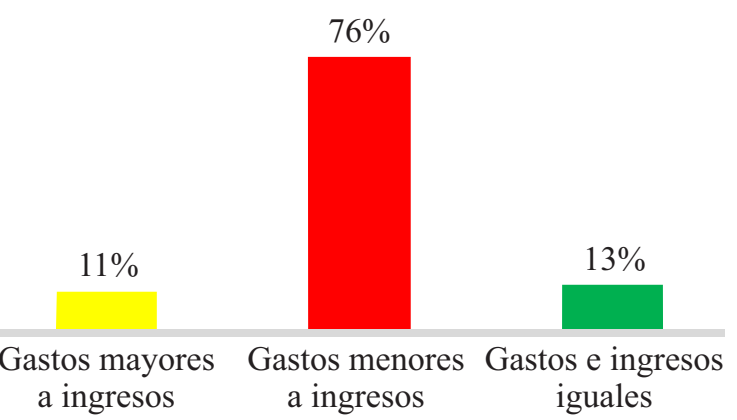

Figure 6. Relación que existe ente sus gastos e ingresos.

En la figura $\mathrm{N}^{\circ} 6$, se muestra que el $11 \%$ de la población de estudio respondió que sus gastos son mayores a sus ingresos, el 76\% dijo que sus gastos son menores a sus ingresos y el $13 \%$ afirmó que sus gastos e ingresos son iguales.. 


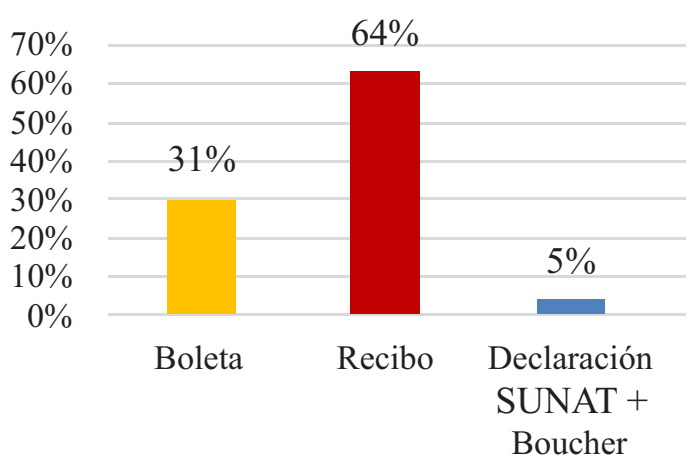

Figure 7. Tipo de comprobante utilizan con mayor frecuencia.

En la figura $\mathrm{N}^{\circ} 7$, se muestra que el comprobante de pago más utilizado es el recibo con un $64 \%$, seguido de la boleta con un $31 \%$ y finalmente la declaración Sunat + Boucher con un $5 \%$.

\section{DISCUSIÓN}

(Latínez, 2012) en su investigacion denominada Evasión tributaria en impuesto a la renta, realizada para la SUNAT, indica que: Son rentas de 1era categoría:

$>$ Arriendo y subarriendo de inmuebles (amoblados y sin amoblar)

$>$ Arriendo y subarriendo de bienes muebles (maquinaria, autos, computadoras, etc.)

$>$ Ceder en uso gratuitamente Inmuebles y bienes muebles.

Las personas naturales perceptoras de rentas de primera categoría que alquilan y subarriendan bienes Muebles e Inmuebles tienen que efectuar pagos a cuenta del impuesto a la renta y presentar su Declaración Jurada Anual y pagar el impuesto a la renta anual, previa deducción de los pagos a cuanta del impuesto a la renta. Los que ceden gratuitamente bienes Muebles e Inmuebles tienen que presentar su Declaración Jurada Anual y pagar el impuesto a la renta anual.

La mayoría de perceptores de Rentas de primera categoría no pagan tributos.

En la presente investigación para obtener información, se realizó una encuesta dividida en tres bloques validada, que permitió identificar las características del pago de impuesto a la renta de primera categoría, llegándose a identificar los sostenido por Latinez en cuanto al arriendo y subarriendo de inmuebles para vivienda, en la ciudad de Chachapoyas.

En la investigación se pudo observar que un $70 \%$ de encuestados arriendan sus inmuebles; y según lo sostenido en la investigación evasión tributaria e impuestos a la renta, los arrendantes están obligados a pagar el impuesto a la renta de primera categoría, caso que no sucede en la ciudad de Chachapoyas.

(Cancho, 2016), presenta en sus resultados producto de dicho trabajo de investigación indica que el 100\% de los propietarios de los inmuebles son mayores de edad, entendiendo que la mayoría de edad es después de haber cumplido los 18 años; de igual manera, el $30 \%$ tiene una instrucción superior y el $50 \%$ no cuentan con estudios superiores, entendiendo que solamente pueden haber tenido estudios secundarios; estos resultados guardan similitud con los encontrados en la presente investigación, considerando que es un requisito para realizar toda transacción de arrendamiento, ser mayor de edad.

Posteriormente, luego de detectar según el trabajo de investigación quienes eran los que arrendaban sus inmuebles, se pudo detectar que solo un $30 \%$, no alquila sus inmuebles o propiedades, por tal motivo se continuo con la encuesta a las personas que si arrendaban sus propiedades, y se pudo detectar que muchos de los propietarios cuentan hasta con 16 habitaciones, por lo que se considera que verdaderamente, el arriendo es un negocio exitoso, pero, que puede ser un síntoma de enriquecimiento ilícito y hasta lavado de activos por cuanto no pagan ningún tipo de impuesto.

También, se pudo determinar que muchos de los propietarios arriendan sus propiedades con todas las comodidades que se desea, como ser amobladas y por dicho concepto se puede cobrar algo más; también, se pudo detectar que en el alquiler de locales comerciales no incluye el pago de servicios públicos, como es la energía eléctrica, agua y teléfono y en algunos casos los arbitrios municipales, como limpieza pública y otros.

Como parte del alquiler, los propietarios para poder arrendarlos previamente lo acondicionaban para tal fin, por lo que efectuaban algunos gastos adicionales, los mismos que muchos de ellos no contaban con el sustento de dichos gastos y ponerlos a buen servicio de los futuros arrendatarios.

También se pudo detectar que el costo de arriendo oscila entre S/ 100 y mayor a S/ 2,100, lo de menor costo es para estudiantes y los mayores de $\mathrm{S} / 2,100$ es para locales comerciales.

Existen trabajos relacionados con el mismo y de igual manera se coincide con el resultado del trabajo 
efectuado, por lo que se considera que el arrendamiento es un negocio muy rentable y que sería muy conveniente que la SUNAT oriente a los contribuyentes y luego poder obtener mayores ingresos tributarios, lo que redundaría en el crecimiento del PBI y por consiguiente mayor recaudación tributaria por concepto de renta de primera categoría.

Para concluir, con la presente investigación se pudo detectar que existe una gran parte de los arrendatarios que no emite ningún tipo de documento y solo lo hacen con un recibo simple, lo sostenido en este párrafo es como un denominado a nivel nacional, considerándose a este tipo de evasión tributaria.

\section{CONCLUSIONES}

$>$ Los propietarios de los inmuebles del distrito de Chachapoyas son mayores de edad, con preferencia del género femenino y cuentan con estudios secundarios.

$>$ Los propietarios consideran al arriendo como un negocio exitoso, el mismo que puede ser un síntoma de enriquecimiento ilícito y lavado de activos, por cuanto no pagan ningún tipo de impuestos.

$70 \%$ de propietarios no emiten ningún tipo de documentos y se limitan a entregar un recibo simple, esto se da con mayor incidencia en estudios, los inmuebles alquilados para el comercio son los que presentan entrega de comprobantes de pago.

\section{RECOMENDACIONES}

Se recomienda a las entidades pertinentes generar una política pública para promover el alquiler de inmuebles para vivienda de manera legal sin evasión tributaria.

\section{REFERENCIAS}

Aznarán, \& Sánchez. (2011). Complementación del control fiscal para mejorar la recaudación del impuesto a la renta de primera categoría por el arrendamiento de inmuebles en el departamento de La Libertad. Obtenido de http://repositorio.upn.edu.pe/: : http://repositorio.upn.edu.pe/xmlui/handle/ 11537/102.

Cancho. (2016). La evasión tributaria por parte de los contribuyentes afectos a la renta de primera categoría y sus alternativas de mejora en los gobiernos locales del Perú. Facultad de Economía y Contabilidad: Pontificia Universidad Católica del Perú.

Latínez. (2012). Evasión tributaria en impuesto a la renta. Facultad de Contabilidad: Universidad de San Martín de Porres.

Rivas, \& Paillacar. (2007). Caracterización de la elusión fiscal en el impuesto a la renta de chile. CAPIV REVIEW Vol. 5, 14. : Obtenido de capic.cl. 